\title{
CAN ULTRA-VIOLET MIE LIDAR BE AN EFFECTIVE INSTRUMENT DURING HIGH POLLUTION EPISODE?
}

\author{
Qiaojun Liu ${ }^{1 *}$, Zhangjun Wang ${ }^{1}$, Libin Du ${ }^{1}$, Andrew Yuk Sun Cheng ${ }^{1}$, Xiangqian Meng ${ }^{1}$, Chao \\ Chen ${ }^{1}$, Xianxin $\mathrm{Li}^{1}$, Xingtao Liu ${ }^{1}$ \\ ${ }^{1}$ Shandong Academy of Sciences Institute of Oceanographic Instrumentation, Qingdao266001, China, \\ *Email:qiaojunliu@163.com
}

\begin{abstract}
Vertical profiles of particulates were measured by a $355 \mathrm{~nm}$ Mie scattering lidar during a dust-storm event. A high energy pulse laser was employed as the light source to detect the extinction coefficient in the altitude up to $6 \mathrm{~km}$ in the day and $9 \mathrm{~km}$ at night. The extinction profiles showed layers of high aerosol concentrations in good agreement with ground-based pollution measurements, which indicated that such ultra-violet lidar is a very useful remote sensing instrument for monitoring extinction profiles during extreme high aerosol loading and low visibility atmospheric conditions when low energy lidar systems cannot obtain effective results.
\end{abstract}

\section{INTRODUCTION}

Air quality is always of great concerns. The particulate concentration keeps increasing in China over the past 20 years with the rapid economic development. Numerous ground stations make continuous round-the-clock point measurements of a range of pollutants, but they seldom provide the pollutants vertical profile which is important for modelling the transport of pollution. With good spatial and temporal resolution, real-time measurements can now be obtained from remote sensing technique such as lidar. Lidar has been widely employed to study aerosol spatial distribution [1] and explore the transport of aerosols over larger areas ${ }^{[2]}$. During episodes of dust event, lidars are important monitoring instruments ${ }^{[3,4]}$.

There is an internal relation between aerosol extinction and mass concentration. Without information on the particle size distribution and complex refractive index, the aerosol mass concentration can be retrieved from Mie lidar data using statistical correlations ${ }^{[5]}$. It is possible to extract aerosol mass concentrations within a reasonable accuracy of $20-30 \%$ without supplementary information on the aerosols ${ }^{[6,7]}$. With varying refractive index, Del Guasta [8] obtained aerosol mass concentrations $40 \mathrm{~m}$ above the ground from lidar measurements.

In this paper, rough proportionality between accumulation-mode aerosol mass concentration and lidar extinction is reported. The current work aims to infer vertical profiles of $\mathrm{PM}_{10}$ using a single channel lidar. Mass concentrations are inferred by establishing empirical correlations between $\mathrm{PM}_{10}$, visibility and extinction coefficient. In Section 2, the lidar instrumentation and data analysis method are described. Then, in Section 3, some results and discussions from dust case measurement are presented. And Section 4 is the conclusion.

\section{METHODOLOGY}

The lidar system used for the study, is a single wavelength Mie lidar located on top of the Taipa Grande in Macao at $112 \mathrm{~m}$ above sea level. The third harmonics of Nd:YAG laser is chosen as the emitter laser source with a pulse width of $5.7 \mathrm{~ns}$ at $50 \mathrm{~Hz}$. The maximum pulse energy of the laser is $160 \mathrm{~mJ}$, which is set to at most $50 \%$ of the maximum capacity in routine aerosol monitoring.

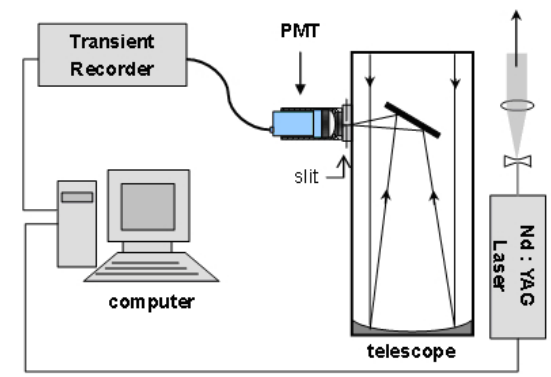

Figure 1. Configuration of $355 \mathrm{~nm}$ bi-static aerosol lidar system

The system layout is depicted in Figure 1. In the daytime, the sky background radiation in ultraviolet wavelength range is much weaker than 
that in the visible wavelength range. Under extremely high atmospheric extinction conditions this lidar can still obtain aerosol profiles up to 6 $\mathrm{km}$ in the day and $9 \mathrm{~km}$ at night.

The Fernald's method ${ }^{[9]}$ is used to retrieve the extinction coefficient. The molecular Rayleigh scattering values referred were taken from the US Standard Atmosphere (1976), the lidar ratio was assumed to be $50 \mathrm{sr}$ for all data presented here, based on data from a Raman lidar operated in the Pear River Delta region near Hong Kong ${ }^{[10]}$. The boundary condition was the assumption that the lidar could transmit far enough and the far range aerosol extinction was zero. In general, aerosol concentrations are higher and vary sharply near the surface, therefore, capturing values of the near range is important for air quality studies. Near range correction of the lidar signal followed the methods proposed by A.Y.S Cheng et al. ${ }^{[11]}$ and Liu et al. ${ }^{[12]}$.

\section{RESULTS}

Figure 2 presents the $\mathrm{PM}_{10}$ and $\mathrm{PM}_{2.5}$ concentration in the dust episode in March, 2010. A significant increase of $\mathrm{PM}_{10}$ and $\mathrm{PM}_{2.5}$ concentration was found after March $21^{\text {st }}$. Before that day, the $\mathrm{PM}_{10}$ concentration was much lower, and the average value was only $60.40 \mu \mathrm{g} / \mathrm{m}^{3}$. $\mathrm{PM}_{10}$ concentration had a weak growth on $21^{\text {st }}$, however, at 18:00 on $21^{\text {st }}$, it increased rapidly. At $5: 30$ on $22^{\text {nd }}$ it was up to the maximum value $616.83 \mu \mathrm{g} / \mathrm{m}^{3}$, which was ten times more than the average value before. Then the high concentration maintained for a period of time and slowly decreased subsequently. Data showed the concentration decreased to $30.45 \mu \mathrm{g} / \mathrm{m}^{3}$ on $24^{\text {th }}$. By comparing the two lines in figure 2, it can be found that during the dust period, particles of large size $(2.5 \sim 10 \mu \mathrm{m})$ are three times more than the small particles $(2.5 \mu \mathrm{m}$ or less $)$.

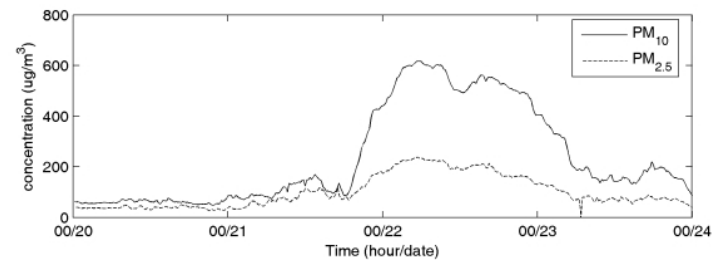

Figure 2. Particulates concentration between March $20^{\text {th }}$ and March $24^{\text {th }}$
The extinction coefficients inverted from Mie lidar in suit measurement are present in Fig.3. Each of these profiles is the average result in an hour, with the starting time on the top. It can be seen that on $22^{\text {nd }}$, when the pollution is heavy, the particles congregation in the low altitude was evident. The extinction coefficients near the ground exceeded $0.7 \mathrm{~km}^{-1}$, which decreased rapidly from the maximum value about $0.9 \mathrm{~km}^{-1}$ at the low height to no larger than $0.3 \mathrm{~km}^{-1}$ at about $0.9 \mathrm{~km}$. However, on $26^{\text {th }}$, the moderate pollution day, the downtrend of extinction was not as sharp, and the near-surface extinction coefficients on $22^{\text {nd }}$ was larger than that on $26^{\text {th }}$.

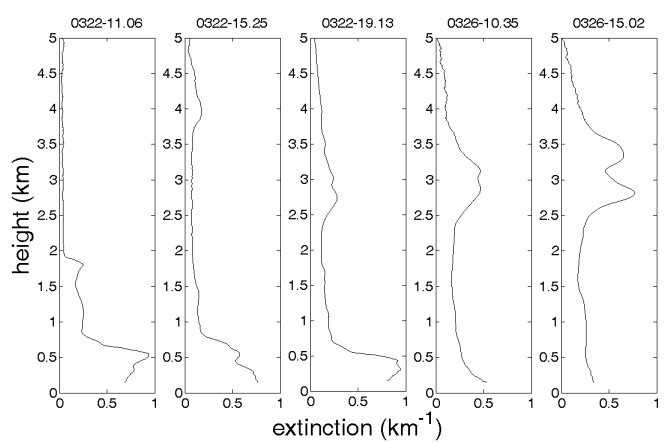

Figure 3. Extinction coefficients inverted from Mie lidar

Comparing the extinction coefficients with $\mathrm{PM}_{10}$ concentrations in heavy polluted episode with that of moderate polluted episode, we find an interesting phenomenon. That is, though the $\mathrm{PM}_{10}$ concentration has fallen from high pollution episode value (average value of $527.49 \mu \mathrm{g} / \mathrm{m}^{3}$ on the $22^{\text {nd }}$ ) to a normal level (average value of $97.25 \mu \mathrm{g} / \mathrm{m}^{3}$ on $26^{\text {th }}$, which is less than one-fifth of the high pollution episode) before the dust-storm event, the near-surface extinction coefficients from lidar measurements didn't show such difference. Lidar measurements showed that the impact by dust particles had not yet been over on $26^{\text {th }}$. There are two main reasons for explaining the disagreement between $\mathrm{PM}_{10}$ concentrations and extinction coefficients. On one hand, as is known, the variation of return signals caused by different particle size-distribution will impact the extinction coefficient retrieval from lidar measurement. In the heavy polluted episode, the bigger particles are the major component of aerosol. But they have a weaker influence on extinction in our back-scattering Mie lidar system, 
for their scattering energy is mainly concentrated in the forward. On the other hand, compared to the rapidly dropped bigger particles, the smaller particles can stay longer in the atmosphere (about one week). So extinction coefficients on $26^{\text {th }}$ are still at a high level.

Based on these two reasons, extinction coefficients at $355 \mathrm{~nm}$ are not sufficient to show the impact of dust particles on atmosphere. Figure 4 shows the near-surface extinction coefficients at $1064 \mathrm{~nm}$ converted from $355 \mathrm{~nm}$ results ${ }^{[13]}$ and $\mathrm{PM}_{10}$ concentration values at the same time. The correlation is helpful for inferring the vertical profiles of $\mathrm{PM}_{10}$ concentration in the dust episode and tracing the possible aerosol sources.

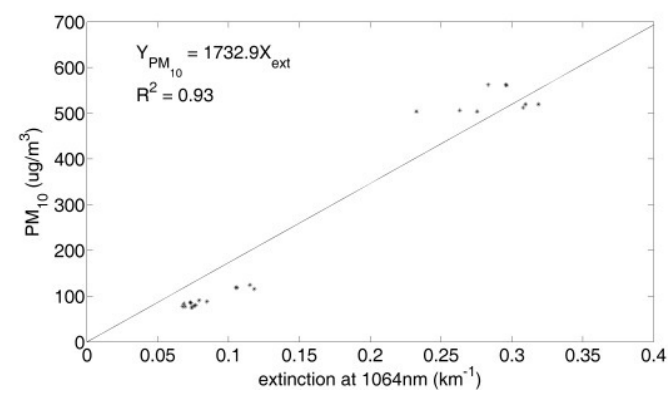

Figure 4. The agreement between extinction coefficient inverted from lidar and $\mathrm{PM}_{10}$ concentration

\section{CONCLUSIONS}

Aerosol extinction coefficients were measured by using the ultra-violet Mie lidar in a high pollution episode, which is the first study of aerosol extinction vertical profiles in a dust-storm event using lidar in Macao. The results show that the ultra-violet lidar has obtained good vertical profiles during the high pollution environment when other low energy lidar systems are ineffective.

\section{ACKNOWLEDGEMENT}

The work described in this paper is supported by the Shandong province excellent young and middle-aged scientists research award fund with grant No. BS2014HZ009, the Progress Program of Science and Technology of Shandong with grant No. 2014GSF117006, the Public science and technology research funds projects of ocean with grant No. 201205036, the International Science \& Technology Cooperation Program of China with grant No. 2011DRF20090 and the Shandong province excellent young and middle-aged scientists research award fund with grant No. BS2012HZ014.

\section{REFERENCES}

[1]Pelon, J., C. Flamant, P. Chazette, J.-F. Leon, D. Tanre, M. Sicard, and S. K. Satheesh, 2002: Characterization of aerosol spatial distribution and optical properties over the Indian Ocean from airborne LIDAR and radiometry during INDOEX'99, J. Geophys. Res., 107(D19), 8029.

[2]Strawbridge, K. B., Snyder, B. J., 2004: Daytime and nighttime aircraft measurements showing evidence of particulate matter transport into the northeastern valleys of the Lower Fraser Valley BC, Atmospheric Environment, 38, 58735886.

[3]G. P. Gobbi, F. Barnaba, R. Giorgi, and A. Santacasa, 2000: Altitude-resolved properties of a Saharan dust event over the Mediterranean, Atmospheric Environment ,34, 5119-5127

[4]Chenbo Xie, Tomoki Nishizawa, Nobuo Sugimoto, Ichiro Matsui, and Zifa Wang, 2008: Characteristics of aerosol optical properties in pollution and Asian dust episodes over Beijing, China. Applied Optics, 47(27), 4945-4951.

[5]Tam, K., et al, 2008: Studies of Urban Aerosols in Macao using a Horizontal Mie Lidar, Journal of Light Scattering, 20(4), 375-378.

[6]Kent, G.S., 1978: Deduction of aerosol concentrations from $1.06 \mu \mathrm{m}$ lidar measurements, Applied Optics, 17(23), 3763-3773.

[7]Del Guasta, M., Marini, S., 2000: On the retrieval of urban aerosol mass concentration by a 532 and $1064 \mathrm{~nm}$ lidar, Journal of Aerosol Science, 31, 1469-1488.

[8]Del Guasta, M., 2002: Daily cycles in urban aerosol observed in Florence (Italy) by means of an automatic 532-1064nm lidar, Atmospheric Environment, 36, 2853-2865.

[9]Fernald, F.G., Herman, B.M., Reagan, J.A., 1972: Determination of aerosol height distribution by lidar, Journal of Applied Meteorology, 11, 482489.

[10]Ansmann, A., Engelmann R., Althausen, D., Wandinger, U., Hu M., Zhang, Y., He, Q., 2005: 
High aerosol load over the Pearl River Delta, South China, observed with Raman lidar and Sun photometer, Geophysical Research Letters, 32(13), L13815.

[11]Andrew Y. S. Cheng, Andrew Walton and Johnny C. L. Chan, 2003: Urban aerosols spatial variations using a slant angle scanning Mie Lidar system. In the SPIE's 3rd International AsiaPacific Symposium on Remote Sensing of the Atmosphere, Environment and Space, October 2327, 2002, Proc. SPIE Volume 4893, 17-24.

[12]Liu Qiao-jun, Yang Lin, Wang Jie-Yu, Zuo Hao-yi, Luo Shi-Rong, Andrew Y. S. Cheng, 2009: Calculation of the overlap factor and correction of near-field signal of the off-axis lidar based on the Gaussian mode of laser beam, Acta Physica Sinica, 58(10), 7376-7381.

[13]Inaba, H., 1976: Detection of atoms and molecules by Raman scattering and resonance fluorescence, in Laser Monitoring of the Atmosphere, chap. 5, Ed. Hinkley E.D., SpringerVerlag. 